\title{
Characterization of a pumpkin mRNA encoding a Cyclin-Dependent Protein Kinase (CDK) potentially involved in phloem development
}

\author{
Paul Starsky Herrera-Pola, Beatriz Xoconostle-Cázares, Roberto Toscano-Morales, Roberto Ruiz- \\ Medrano*
}

Department of Biotechnology and Bioengineering CINVESTAV-IPN, Ave. IPN 2508, Zacatenco, 07360 México DF, México

*Corresponding author: rmedrano@cinvestav.mx

\begin{abstract}
The phloem is involved in the delivery of nutrients but also of long-range signals that regulate diverse processes. Several different RNAs have been found in the phloem translocation stream, which could have a role in signaling. In a previous work, we have found several RNAs in pumpkin phloem sap exudates in response to viral infection, among them a transcript encoding a potential cyclindependent protein kinase (CDK). In this study, we report the further characterization of the aforementioned CDK mRNA. The

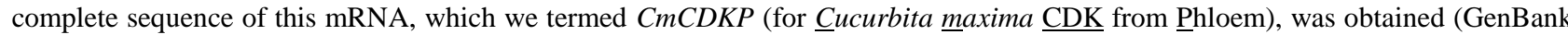
no. AIQ82912.1). The phylogenetic analysis of the virtual translation of this sequence showed that CmCDKP is closely related to those involved in transcriptional regulation via RNA polymerase II CTD phosphorylation, or splicing control. The mRNA accumulated to highest levels in pollen tissue. Interestingly, the mRNA localized to the companion cell-sieve element complex in the phloem, developing phloem, and also in isolated cells in the shoot apical meristem, suggesting a role in early phloem development.
\end{abstract}

Keywords: RNA transport, Phloem development, CDKs, transcription regulation. Abbreviations: CDK, Cyclin-Dependent protein Kinase; CC-SE Companion Cell-Sieve Element complex.

\section{Introduction}

The vascular tissue was likely a powerful driving force behind the colonization of terrestrial habitats by plants, and also having an important role in its diversification. The most important function of the vasculature is nutrient transport, the xylem being involved in the distribution of water and mineral nutrients while the phloem of fixed carbon throughout the whole plant (Lough and Lucas, 2006; Lucas et al., 2013). The phloem consists mainly of two cell types, the companion cell (CC) and the enucleated sieve element (SE), which are interconnected through branched plasmodesmata (Lucas et al., 2013). The files of SEs form a network that effectively maintains distant parts of the plant communicated (Lucas et al, 2013). It has become increasingly clear, though, that the phloem is also involved in the delivery of signals that may regulate whole-plant development and response to environmental cues (Lough and Lucas, 2006; Kehr and Buhtz, 2008; Lucas et al., 2013). Potential long-range signals include phytohormones, proteins, lipids, and different types of RNA (mRNAs and small RNAs) (Lucas and Lough, 2006; Lucas et al., 2013). Flowering in response to photoperiod, tuberization, response to phosphate starvation and post-transcriptional gene silencing (PTGS) are examples of phloem-transported regulatory proteins and RNAs (Corbesier et al., 2007; Lin et al., 2007; Yoo et al., 2004; Kehr and Buhtz, 2008; Navarro et al., 2011). Massive long-distance transport of RNA in Arabidopsis and grapevine grafts, and between a parasite plant and its host suggests that this phenomenon is important for plant viability, although its global physiological significance is not yet clear (Kim et al., 2014; Thieme et al., 2015; Yang et al., 2015).

We have previously reported that the phloem sap of Cucumber mosaic virus-infected Cucurbita maxima (pumpkin) cv. Big Max contains differentially-accumulated mRNAs, some of which could represent signals involved in establishing a defense response against pathogen attack (Ruiz-Medrano et al., 2007). In the present work we report further characterization of a differentially accumulated transcript coding for a putative Serine-Threonine protein kinase, possibly involved in signaling, a notion supported by the presence of the corresponding transcript in the phloem translocation stream. Here, we report the full-length sequence of the transcript, which was termed $C m C D K P$ (for Cucurbita maxima Cyclin-Dependent Protein Kinase from Phloem) and corresponds to a Cyclin-dependent protein kinase (CDK). CDKs are key regulators of cell cycle progression in all eukaryotes, and in plants link phytohormone signaling and environmental cues to the cell cycle via phosphorylation of transcription factors that promote cell cycle progression (Joubès et al., 2001; Komaki and Sugimoto, 2012). There are several types of CDKs, which include non-canonical ones, whose main roles appear to regulate transcription elongation and splicing of genes that are not directly involved in cell cycle progression, as well as in modification of chromatin (Tanny et al., 2014; Hydbring et al., 2016). Indeed, a closer 
inspection of the sequence, as well as phylogenetic analysis supported the grouping of this protein with type C CDKs. These proteins do not regulate directly the cell cycle; rather, a role of some members of this clade in response to biotic and abiotic stress through regulation of transcription and/or splicing has been demonstrated (Huang et al., 2008; Kitsios et al., 2008; Li et al., 2014). On the other hand, the localization of this mRNA suggests an involvement in early vascular tissue and phloem development.

\section{Results and Discussion}

CmCDKP is phylogenetically related to CDKs involved in transcriptional regulation

We have previously reported the presence of an mRNA encoding a putative cyclin-dependent protein kinase (CDK) in phloem sap exudates of pumpkin experimentally infected with Cucumber mosaic virus using subtractive suppressive hybridization, which we termed $C m C D K P$ (for $\underline{C} u c u r b i t a$

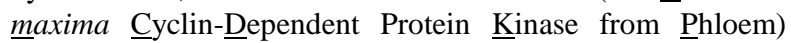
(Ruiz-Medrano et al., 2007). A 433 bp cDNA fragment was originally cloned using this strategy; to obtain the full-length Open Reading Frame 5' and 3' RACE was used. For the latter a specific internal primer and an oligo dT-GAGA primer were used. As for the $5^{\prime}$ end, after a general amplification step involving the SMART primer, several plant CDK protein sequences were aligned to obtain a more conserved consensus. Both the 5'-and $3^{\prime}$-RACE products were cloned and sequenced, and the full-length obtained by RT-PCR using specific primers. This sequence was aligned using ClustalX and subsequently analyzed to determine its relationship with other CDK sequences. Sequences from major plant species were retrieved and used to construct a phylogeny based on the Neighbor-Joining method (Fig. 1). According to this phylogeny, CmCDKP is more closely related to CDKs that may not be involved in cell cycle regulation. Indeed, the type member of this clade to which CmCDKP belongs, and which has been extensively studied, the human CDK9, which is part of the CDKC family, has an important role in transcription elongation by interaction with and phosphorylation of the RNA polymerase II CarboxyTerminal domain (CTD) (Tanny, 2014; Hydbring et al., 2016). This analysis shows that the CDK9-like clade containing CmCDKP is quite large; a possible role in transcriptional elongation can only be assigned to these proteins by analogy since most sequences in this phylogeny are hypothetical. Another member of the CDK9 clade, CDKC2 from Arabidopsis, colocalizes with spliceosomal components and regulates their distribution; further, they have a role in immunity to microbial pathogens since they mediate the response to bacterial effectors (Kitsios et al., 2008; Li et al., 2014). Indeed, it is becoming more evident that CDKs, and in particular non-canonical ones, have more diverse roles than previously thought, such as in immunity, regulation of cell death and DNA repair (Hydbring et al., 2016). A more distant sequence relative to this clade, CDKG from Arabidopsis, regulates the splicing of callose synthase 5, involved in pollen wall formation (Huang et al., 2013).

This supports the notion that members of these clades have a role in transcriptional elongation and splicing of certain transcripts. On the other hand, the induction of $C m C D K P$ mRNA in response to CMV infection is consistent with a role in defense response to pathogen attack (Ruiz-Medrano et al., 2007).
CmCDKP mRNA accumulates to highest levels in floral organs

Next, quantitative RT-PCR analysis was carried out to determine the transcript levels of $C m C D K P$ mRNA. The highest levels found were in pollen and mature flowers, and, to lesser extent, in flower buds and source leaves (Figure 2). These results lend support to the notion that CmCDKP may have a role in pollen formation, since another member of the CDK9 clade is involved in the formation of pollen wall via splicing of callose synthase 5 mRNA (Huang et al., 2013). Surprisingly, lowest levels were found in stems, vascular strips and phloem sap exudates, even though CmCDKP mRNA was originally found in phloem sap exudates (RuizMedrano et al., 2007). It was thus necessary to analyze with more detail the accumulation pattern of $C m C D K P$ mRNA, which could hint to its function in adult plants.

CmCDKP mRNA localizes to developing phloem and shoot apical meristem

Paraffin-embedded sections were hybridized with sense and antisense in vitro transcribed $C m C D K P$ probe, which was labeled with digoxigenin. Sections from apices and petioles from four-week old pumpkin plants were analyzed with more detail. In the case of apical tissues, strong signal corresponding to this transcript was detected in isolated cells close to the meristem proper (Fig. 3B). In sections further away from the apex signal was detected in what appear to be vascular initials, while in leaf primordia the transcript was observed either in small clusters of cells or single isolated cells; in more basipetal regions the $C m C D K P$ transcript clearly localizes to the CC-SE complex (Fig. 3C, D and I). These results suggest that the $C m C D K P$ gene has a role in early vascular development. $C m C D K P$ antisense transcript yielded also a strong signal in developing and mature phloem from petiole and young stem cross sections (Fig. 3F and $\mathrm{H}$ ). Interestingly, a specific signal was also detected in the extrafascicular developing phloem (Fig. 3J and K). It must be mentioned that it has been suggested that in cucurbits photoassimilates are distributed through the internal phloem, while the external phloem could be involved in long-distance signaling (Wang et al., 2010). Furthermore, CmNACPI mRNA is transmitted through a graft union from a pumpkin stock to a cucumber scion via the extrafascicular phloem (Ruiz-Medrano et al., 1999), which is again consistent with a role in phloem long-distance signaling. CmCDKP could be involved in development of extrafascicular phloem, but given that the mRNA apparently localizes also to sieve elements here, a role in signaling cannot be discarded. It has recently been envisaged that certain CDKs have role that may not be related directly to cell cycle regulation (Hydbring et al., 2016). Indeed, in the case of mammalian CDKs, only a few have been shown to be involved in such activity; as mentioned before, members of several types of CDKs have a more direct role in splicing and/or transcriptional regulation, although this has been elucidated for only a few species. Thus, it is necessary the analysis of CDKs from diverse organisms to search for general functions of these proteins, if any. 
Table 1. Accession numbers of protein sequences used to construct CmCDKP phylogeny.

\begin{tabular}{|c|c|c|}
\hline Name or sequence ID & Genbank Accession number & Organism \\
\hline $\mathrm{CmCDKP}$ & KM058713.1 & Cucurbita maxima \\
\hline Cucsa.289140.1 & XP_004135651.1 & Cucumis sativus \\
\hline AT1G54610.1 & NP_175862.1 & Arabidopsis thaliana \\
\hline Manes.09G159000.2.p & CK650678.1 & Manihot esculenta \\
\hline LOC8288455 & XP_002512278 & Ricinus communis \\
\hline Lus 10004144 & N.D. & Linum usitatissimum \\
\hline Potri.005G045500.1 & XP_006382713.1 & Populus trichocarpa \\
\hline Medtr7g114300.1 & XP_003626368.1 & Medicago truncatula \\
\hline Phvul.006G097500.1 & XP_007147119.1 & Phaseolus vulgaris \\
\hline Glyma03g40330.1 & XP_003521735.1 & Glycine max \\
\hline ppa003511m & XP_007222466.1 & Prunus persica \\
\hline MDP0000742986 & XP_008388632.1 & Malus x domestica \\
\hline 101304233 & XP_004289615.1 & Fragaria vesca \\
\hline ARALYDRAFT_495150 & XP_002865826.1 & Arabidopsis lyrata \\
\hline Carubv $10020060 \mathrm{~m}$ & XP_006302071.1 & Capsella rubella \\
\hline $\mathrm{Bra027966}$ & XP_009113426.1 & Brassica rapa \\
\hline Thhalv10023378m & XP_006392507.1 & Thellungiella halophila \\
\hline evm.TU.contig_28523.3 & EX233665.1 & Carica papaya \\
\hline Gorai.007G287200.3 & XP_012492925 & Gossypium raimondii \\
\hline Eucgr.H03769.1 & XP_010024564.1 & Eucayptus grandis \\
\hline Solyc01g098160.2 & XP_004230142.1 & Solanum lycopersicum \\
\hline PGSC0003DMT400027661 & XP_006342740.1 & Solanum tuberosum \\
\hline Ciclev10000698m & XP_006433109.1 & Citrus clementina \\
\hline orange1.1g018936m & KDO57098.1 & Citrus sinensis \\
\hline GSVIVT01021907001 & XP_002273085.1 & Vitis vinifera \\
\hline Thecc1EG026444t2 & XP_007030691.1 & Theobroma cacao \\
\hline Migut.N00122.1 & XP_012841047.1 & Mimulus guttatus \\
\hline Aquca_003_00886.3 & N.A. & Aquilegia coerulea \\
\hline LOC_Os07g47180.1 & XP_015647038.1 & Oryza sativa \\
\hline Seita.2G424100.1 & XP_012699221.1 & Setaria italic \\
\hline Bradi1g18450.1 & XP_003562490.1 & Brachypodium distachyon \\
\hline Sobic.001G372900.1 & KXG39386.1 & Sorghum bicolor \\
\hline GRMZM5G873277 & XP_008670639.1 & Zea mays \\
\hline Pavir.Bb03658.1 & XP_010105022.1 & Panicum virgatum \\
\hline Pp3c9_21750V3.3 & XP_001784887.1 & Physcomitrella patens \\
\hline $14545 \overline{7}$ & XP_002968148.1 & Selaginella moellendorffii \\
\hline 36844 & XP_005647315.1 & Coccomyxa subellipsoidea \\
\hline Cre10.g465900.t1.2 & XP_001698637.1 & Chlamydomonas reinhardtii \\
\hline Vocar.0008s0098.1 & XP_002954450.1 & Volvox carteri \\
\hline
\end{tabular}

\section{Materials and Methods}

\section{Plant material}

Cucurbita maxima Big Max seeds (RH Shumway's; Randolph, WI) were placed in germination trays containing cotton saturated with water and maintained in a greenhouse until germination, usually for 1 week. Seedlings were then transferred to pots with $5 \mathrm{~kg}$ of soil (mixed) and irrigated with nutrient solution every 3 days until used.

\section{Cloning procedures and quantitative RT-PCR analysis}

To obtain the full-length $C m C D K P$ open reading frame (ORF), $100 \mathrm{mg}$ of pumpkin petiole tissue was disrupted using a TissueLyser LT (Qiagen, Hilden, Germany), and RNA extracted using an RNeasy kit (Qiagen), essentially following the manufacturer's recommendations. The RNA was eluted

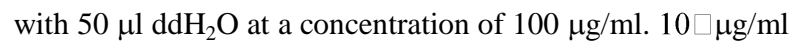
dilutions of were used as template for cDNA synthesis using Superscript II reverse transcriptase (Invitrogen, La Jolla CA). 5'- and 3' -RACE using dTGAGA and SMART primers according to Diatchenko et al. (1996). The 5'-end of the CmCDKP ORF was obtained using as reverse primer a sequence within the original $C m C D K P$ fragment obtained by subtractive cloning (Ruiz-Medrano et al., 2007) (5'TTTCGGGAGGCTAGAGGGTTTGCAAGC-3'). The forward primer was designed based on the alignment of the 5, ends of the closest homologues of CmCDKP in Cucumis melo, Cucumis sativus, and Arabidopsis (NCBI accession Nos. XP_008450739.1 and XP_004135651.1, respectively) (sequence 5'-ATGGGGTGTYTGGTTAGCCGAGAGGCGTCTTCTAGA-3'). The 3'-end of the sequence was obtained using as forward primer a sequence within the aforementioned original CmCDKP fragment (Cmd19 REV2, 5'- AGCGAGTTCTTCATGACAGAGCCTTTAGCTTGC$3^{\prime}$ ') and as reverse primer the dTGAGA primer. cDNA was first synthesized using Superscript II Reverse Transcriptase, followed by RACE using Takara Taq polymerase(Takara Bio, Japan ), both following the manufacturer's instructions. The conditions for the 5' and 3' RACE were essentially the same, as follows. One cycle of denaturing, $3 \mathrm{~min}$ at $94^{\circ} \mathrm{C}$, followed by 35 cycles of denaturing for $35 \mathrm{sec}$ at $94^{\circ} \mathrm{C}$, annealing for $35 \mathrm{sec}$ at $56^{\circ} \mathrm{C}$ and polymerization for $1 \mathrm{~min} 45 \mathrm{sec}$ at $72^{\circ} \mathrm{C}$, with a final extension step of $7 \mathrm{~min}$ also at $72^{\circ} \mathrm{C}$. The resulting PCR products were cloned in the pDrive vector (Qiagen), and sequenced. 


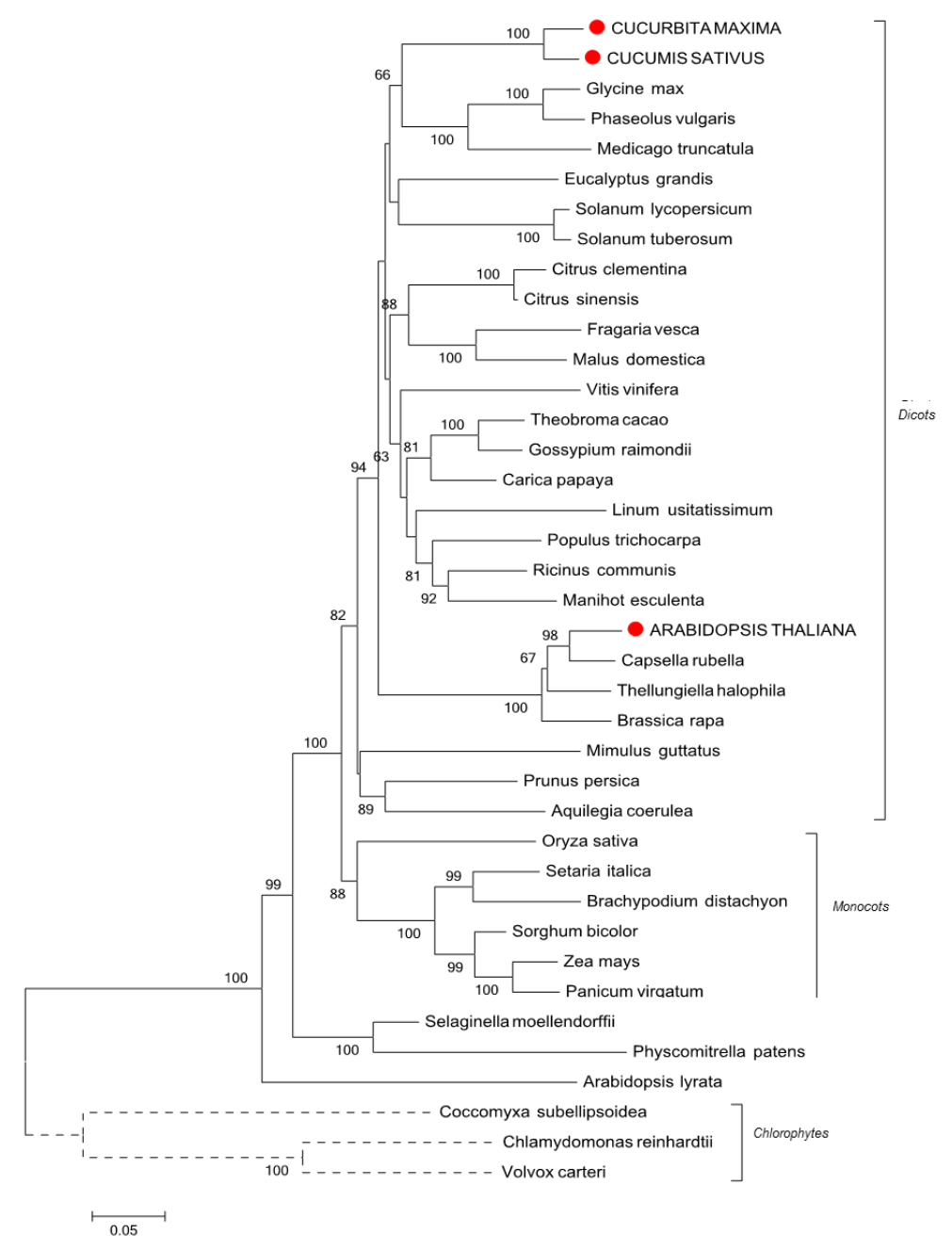

Fig 1. Phylogeny of CmDKP in relation to plant CDKs. Sequences were obtained from Phytozome (https://phytozome.jgi.doe.gov) after BLASTP analysis. The more similar sequences to CmCDKP for each taxon were used. Red dots correspond to CmCDKP, and its closest homologues in C. sativus and Arabidopsis. The phylogenetic tree shows that sequences that cluster with CmCDKP form a large clade, which presumably share common functions.

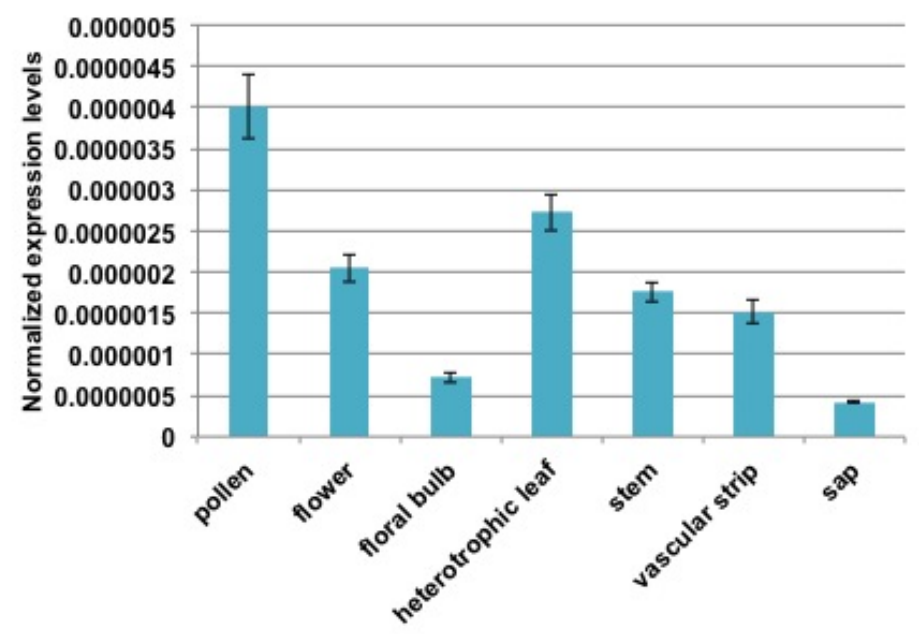

Fig 2. Quantitative RT-PCR analysis of $C m C D K P$ mRNA accumulation in different tissues. Total RNA was isolated from pollen, mature flowers, flower bulbs, heterotrophic leaves, stem, vascular strips and phloem sap. The 2-- $\Delta \mathrm{CT}$ method was used to determine relative amounts of mRNA (Livak and Schmittgen, 2001). Data was normalized to 18S rRNA 

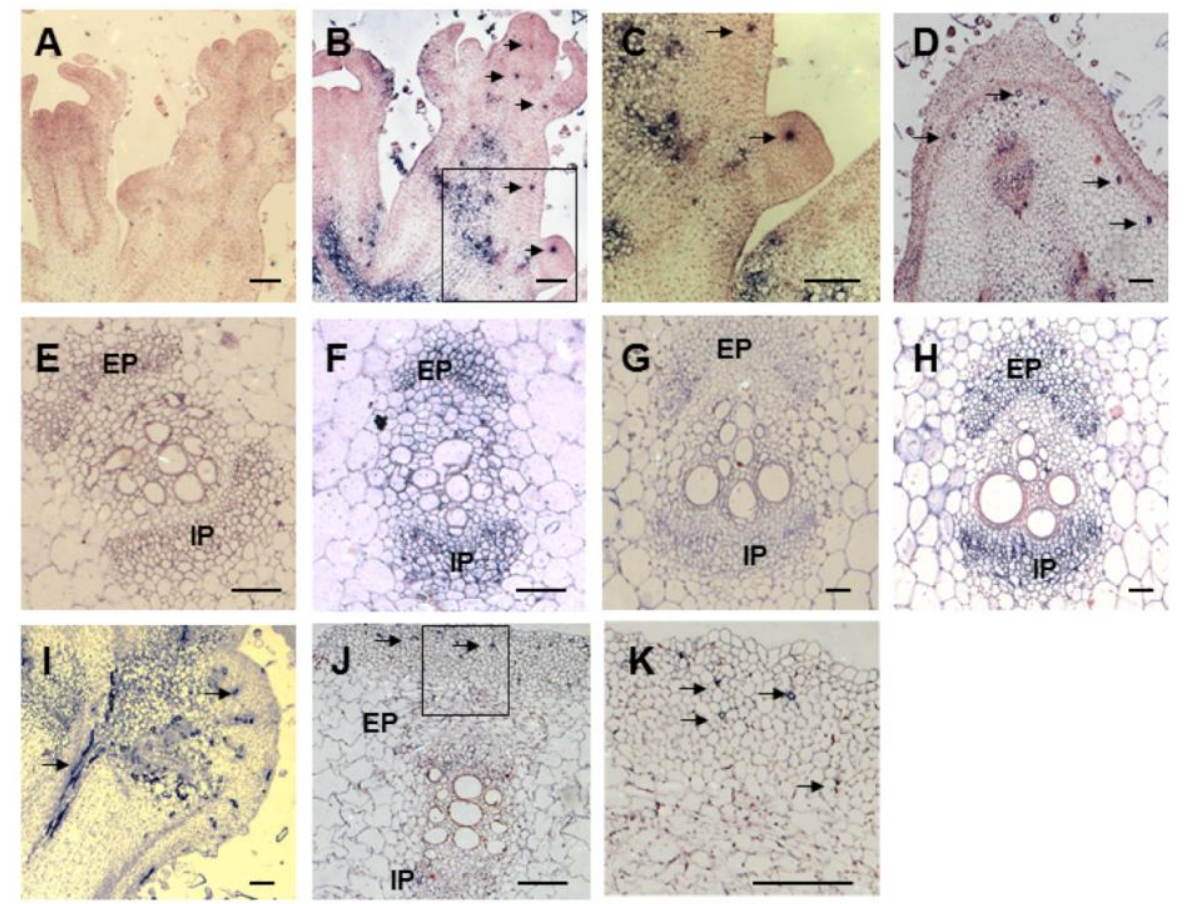

Fig 3. In situ localization of $C m C D K P$ mRNA in different tissues. A, longitudinal section of apex of immature flower hybridized with digoxigenin-labeled sense $C m C D K P$ RNA probe. B, same as A, but hybridized with antisense probe. Arrows indicate hybridization signal in isolated cells or groups of cells close to the apex. C, magnification of the area within the small rectangle in B. $\mathrm{D}$, sagittal section of region close to the apex hybridized to antisense $C m C D K P$ probe; signal in phloem cells is indicated by arrows. $\mathrm{E}$, cross section of petiole of heterotrophic leaf hybridized with sense $C m C D K P$ probe. F, cross section of petiole hybridized to antisense probe. $\mathrm{G}$, cross section of stem close $(10 \mathrm{~cm})$ to the apex, hybridized to sense $C m C D K P$ probe. $\mathrm{H}$, same as $\mathrm{G}$, but hybridized to antisense probe. I, sagittal section of stem close to the apex, hybridized with antisense $C m C D K P$ probe, which includes part of an emerging petiole. Arrows indicate phloem cells. J. Cross section of a petiole of a mature leaf hybridized with antisense CmCDKP probe. Arrows indicate extrafascicular phloem. K, enlarged image showing details of the area in the small rectangle. Arrows indicate individual companion cell/sieve element pairs. Bar is $100 \mu \mathrm{m}$ in all cases, except in D and I, in which it is $200 \mu \mathrm{m}$.

For RT-PCR analysis, CmCDKP RNA levels were determined as follows. Total RNA was extracted from tissues from five independent plants, $50 \mathrm{mg}$ for each tissue (pollen, leaves, stems, apex, flower buds and mature flowers), pooled, and used for one-step RT-PCR (10ng in a $10 \mu \mathrm{L}$ reaction). In the case of phloem sap exudates, RNA was isolated as described previously (Ruiz-Medrano et al., 1999). A commercial system was used according to the manufacturer's recommendations (KAPA SYBR FAST Universal One-Step qRT- PCR Kit). Specific primers used for $C m C D K P$ were: Cmd19 FOR, 5'GTGGCTCCCCTTCAGATGAATATTGGA-3’, and CmdREV2. The Real Time RT-PCR reactions were incubated in a RotorGene 3000 apparatus (Corbett Research, Australia) using the following PCR conditions: 5 min at $42{ }^{\circ} \mathrm{C}$ for reverse transcription followed by $3 \mathrm{~min}$ at $95^{\circ} \mathrm{C}$ with 45 cycles of denaturation $\left(95^{\circ} \mathrm{C}\right.$ for $\left.3 \mathrm{~s}\right)$, annealing $\left(58^{\circ} \mathrm{C}\right.$ for $20 \mathrm{~s})$, and extension $\left(72^{\circ} \mathrm{C}\right.$ for $\left.3 \mathrm{~s}\right)$. To verify that no additional products were amplified in the reaction, a dissociation curve was generated progressive sample heating $\left(60-95^{\circ} \mathrm{C}\right)$. The $\mathrm{Ct}$ value for each product was determined by triplicate for each tissue sample. $18 \mathrm{~S}$ rRNA was used to normalize gene expression; the primers used were: $18 \mathrm{~S}$ FOR, 5'GCCCGGGTAATCTTTGAAATTTCAT-3’; 18S REV, 5'GTGTGTACAAAGGGCAGGGACGTA-3. Relative quantification of transcript accumulation was performed according to the $2-\Delta \mathrm{CT}$ method described by Livak and
Schmittgen (2001). Three repeats were analyzed per tissue.

\section{In situ hybridization}

Tissues from 4-week-old pumpkin plants were excised, fixed, dehydrated and paraffin-embedded, as previously described (Ruiz-Medrano et al., 1999). The original CmCDKP fragment was PCR amplified using specific primers (Cmd19 forward 5'- GTGGAGCAACTACACAAGATATACAAGC - 3' and Cmd19 reverse 5' - CATCTCCTTACTGGGAGGAT -3') and cloned in the pDrive vector (Qiagen). Sense and antisense riboprobes of this fragment were labeled with digoxigenin11-UTP (Roche, México) from linearized plasmid using the Maxiscript T7/Sp6 commercial system, following the manufacturer's recommendations (Ambion, Austin, TX).

\section{Phylogenetic analysis}

Protein sequences of CDKs were retrieved from Genbank and Phytozome (https://phytozome.jgi.doe.gov/pz/portal.html) and aligned using ClustalW Omega (http://www.ebi.ac.uk/Tools/msa/clustalo/). For CmCDKP, this sequence was virtually translated using the Sequence Manipulation Suite (http://www.bioinformatics.org/sms2/) and included in this analysis. A phylogenetic tree was then constructed using Mega 5.1 and the Neighbor-Joining method (Saitou and Nei, 1987). The accession numbers of the sequences utilized in this analysis are listed in Table 1. 


\section{Conclusion}

In the present work we characterized the mRNA for a phloem-expressed Cyclin-Dependent Protein Kinase, termed CmCDKP. Analysis of its sequence indicates that it belongs to a clade whose type member, CDK9, functions in transcriptional regulation via phosphorylation of RNA Pol II CTD. Other close members of this clade are engaged in splicing of specific genes, such as CAL5, necessary for pollen wall formation. A similar role for CmCDKP could thus be suggested. In this particular case, however, a role in early vascular tissue differentiation seems also likely, given the localization of this mRNA in isolated cells close to the apex, as well as in leaf primordia. Sagittal sections close to the apex suggest that these cells become vascular tissue, which evidently become phloem tissue as observed in petioles of mature leaves (Fig.) 3B. A role in long-distance signaling is also suggested by the presence of $C m C D K P$ mRNA in external phloem SEs. More work is required to determine whether the protein localizes to these same cell types. Also, analysis of the mutant of the Arabidopsis homologue, At1g54610, will yield valuable insight on the function of this, and related genes.

\section{Competing Interests}

The authors declare that they have no competing interests.

\section{Acknowledgements}

This work was supported by CONACyT grants nos. 105985 and 156162 to BX-C- and RR-M, respectively. PSH-P and RT-M acknowledge fellowship support from CONACyT México.

\section{Authors' contributions}

RR-M and BX-C designed the experiments, coordinated the work, carried out plant transformation experiments, and wrote the manuscript; PSH-P and BX-C carried out plant transformation assays, PSH-P and RT-M performed quantitative PCR and quantitative RT-PCR assays, and RR$\mathrm{M}$ and BX-C carried out in situ hybridization experiments. All authors read and approved the final version of the manuscript.

\section{References}

Banerjee AK, Chatterjee M, Yu Y, Suh SG, Miller WA, Hannapel DJ (2006) Dynamics of a mobile RNA of potato involved in a long-distance signaling pathway. Plant Cell. 18: 3443-3457.

Corbesier L, Vincent C, Jang S, Fornara F, Fan Q, Searle I, Giakountis A, Farrona S, Gissot L, Turnbull C, Coupland G (2007) FT protein movement contributes to long-distance signaling in floral induction of Arabidopsis. Science. 316: 1030-1033.

Diatchenko L, Lau YF, Campbell AP, Chenchik A, Moqadam F, Huang B, Lukyanov S, Lukyanov K, Gurskaya N, Sverdlov ED, Siebert PD (1996) Suppression subtractive hybridization: a method for generating differentially regulated or tissue-specific cDNA probes and libraries. Proc Natl Acad Sci U S A. 93: 6025-6030.

Giavalisco P1, Kapitza K, Kolasa A, Buhtz A, Kehr J (2006) Towards the proteome of Brassica napus phloem sap. Proteomics. 6: 896-909.
Huang XY, Niu J, Sun MX, Zhu J, Gao JF, Yang J, Zhou Q, Yang ZN (2013) CYCLIN-DEPENDENT KINASE G1 is associated with the spliceosome to regulate CALLOSE SYNTHASE5 splicing and pollen wall formation in Arabidopsis. Plant Cell. 25: 637-648.

Huang YW, Tsay WS, Chen CC, Lin CW, Huang HJ (2008) Increased expression of the rice C-type cyclin-dependent protein kinase gene, Orysa;CDKC; 1 , in response to salt stress. Plant Physiol Biochem. 46: 71-81.

Hydbring P, Malumbres M, Sicinski P (2016) Non-canonical functions of cell cycle cyclins and cyclin-dependent kinases. Nat Rev Mol Cell Biol. 17: 280-292.

Joubès J, Lemaire-Chamley M, Delmas F, Walter J, Hernould M, Mouras A, Raymond P, Chevalier C (2001) A new Ctype cyclin-dependent kinase from tomato expressed in dividing tissues does not interact with mitotic and G1 cyclins. Plant Physiol. 126: 1403-1415.

Karimi M, Inzé D, Depicker A (2002) GATEWAY vectors for Agrobacterium-mediated plant transformation. Trends Plant Sci. 7: 193-195.

Kehr J, Buhtz A (2008) Long distance transport and movement of RNA through the phloem. J Exp Bot. 59: 8592.

Kim G, LeBlanc ML, Wafula EK, dePamphilis CW, Westwood JH (2014) Plant science. Genomic-scale Exchange of mRNA between a parasitic plant and its hosts. Science. 345: 808-811.

Kitsios G, Alexiou KG, Bush M, Shaw P, Doonan JH (2008) A cyclin-dependent protein kinase, $\mathrm{CDKC} 2$, colocalizes with and modulates the distribution of spliceosomal components in Arabidopsis. Plant J. 54: 220-235.

Komaki S, Sugimoto K (2012) Control of the plant cell cycle by developmental and environmental cues. Plant Cell Physiol. 53: 953-964.

Li F, Cheng C, Cui F, de Oliveira MV, Yu X, Meng X, Intorne AC, Babilonia K, Li M, Li B, Chen S, Ma X, Xiao S, Zheng Y, Fei Z, Metz RP, Johnson CD, Koiwa H, Sun W, Li Z, de Souza Filho GA, Shan L, He P (2014) Modulation of RNA polymerase II phosphorylation downstream of pathogen perception orchestrates plant immunity. Cell Host Microbe. 16: 748-758.

Lin MK, Belanger H, Lee YJ, Varkonyi-Gasic E, Taoka K, Miura E, Xoconostle-Cázares B, Gendler K, Jorgensen RA, Phinney B, Lough TJ, Lucas WJ (2007) FLOWERING LOCUS $\mathrm{T}$ protein may act as the long-distance florigenic signal in the cucurbits. Plant Cell. 19: 1488-1506.

Lin MK, Lee YJ, Lough TJ, Phinney BS, Lucas WJ (2009) Analysis of the pumpkin phloem proteome provides insights into angiosperm sieve tube function. Mol Cell Proteomics. 8: 343-356.

Livak KJ, Schmittgen TD (2001) Analysis of relative gene expression data using real-time quantitative PCR and the 2(-Delta Delta C(T)) Method. Methods 25: 402-408.

Lucas WJ, Groover A, Lichtenberger R, Furuta K, Yadav SR, Helariutta Y, He XQ, Fukuda H, Kang J, Brady SM, Patrick JW, Sperry J, Yoshida A, López-Millán AF, Grusak MA, Kachroo P (2013) The plant vascular system: evolution, development and functions. J Integr Plant Biol 55: 294-388.

Lough TJ, Lucas WJ (2006) Integrative plant biology: role of phloem long-distance macromolecular trafficking. Annu Rev Plant Biol. 57: 203-232.

Navarro C, Abelenda JA, Cruz-Oró E, Cuéllar CA, Tamaki S, Silva J, Shimamoto K, Prat S (2011) Control of flowering and storage organ formation in potato by FLOWERING LOCUS T. Nature. 478: 119-122.

Ruiz-Medrano R, Hinojosa-Moya JJ, Xoconostle-Cázares B, 
Lucas WJ (2007) Influence of Cucumber mosaic virus infection on the mRNA population present in the phloem translocation stream of pumpkin plants. Funct Plant Biol. 34: 292-301.

Ruiz-Medrano R, Xoconostle-Cázares B, Lucas WJ (1999) Phloem Long-Distance Transport of CmNACP-1 mRNA: Implications for Supracellular Regulation in Plants. Development. 126: 4405-4419.

Saitou N, Nei M (1987) The neighbor-joining method: a new method for reconstructing phylogenetic trees. Mol Biol Evol. 4: 406-425.

Tanny JC (2014) Chromatin modification by the RNA Polymerase II elongation complex. Transcription. 5: e988093.
Thieme CJ, Rojas-Triana M, Stecyk E, Schudoma C, Zhang W, Yang L, Miñambres M, Walther D, Schulze WX, PazAres J, Scheible W-R, Kragler F (2015) Endogenous Arabidopsis messenger RNAs transported to distant tissues. Nature Plants 1: 1-7.

Yang Y, Mao L, Jittayasothorn Y, Kang Y, Jiao C, Fei Z, Zhong GY (2015) Messenger RNA exchange between scions and rootstocks in grafted grapevines. BMC Plant Biol. 15: 251.

Yoo BC, Kragler F, Varkonyi-Gasic E, Haywood V, ArcherEvans S, Lee YM, Lough TJ, Lucas WJ (2004) A systemic small RNA signaling system in plants. Plant Cell 16: 19792000 . 